\title{
Article
}

\section{Explaining Colour Change in Pyrope-Spessartine Garnets}

\author{
Yan Qiu and Ying Guo *
}

School of Gemmology, China University of Geosciences (Beijing), Beijing 100083, China; qiuyantupian@126.com

* Correspondence: guoying@cugb.edu.cn

\begin{abstract}
A colour-changing garnet exhibits the "alexandrite effect", whereby its colour changes from green in the presence of daylight to purplish red under incandescent light. This study examines this species of garnets as well as the causes of the colour change by using infrared and ultraviolet visible (UV-Vis) spectroscopy. The infrared spectra show that the colour-changing garnets in this paper belong to the solid solution of pyrope-spessartine type. CIE1931 XYZ colour matching functions are used to calculate the colour parameters influencing garnet colour-changing under different light sources. The UV-Vis spectra show two zones of transmittance, in the red region at 650-700 nm and the blue-green region at $460-510 \mathrm{~nm}$. As they exhibit the same capacity to transmit light, the colour of the gem is determined by the external light source. The absorption bands of $\mathrm{Cr}^{3+}$ and $\mathrm{V}^{3+}$ at $574 \mathrm{~nm}$ in the UV-Vis spectra are the main cause of the change in colour. With the increase in the area of peak absorption, the differences in the chroma and colour of the garnet gradually increase in daylight and incandescent light, and it exhibits a more prominent colour-changing effect.
\end{abstract}

Keywords: colour-changing garnet; FTIR; UV-Vis spectra; CIE1931 XYZ colour matching functions

Citation: Qiu, Y.; Guo, Y. Explaining Colour Change in Pyrope-Spessartine Garnets. Minerals 2021, 11, 865. https://doi.org/10.3390/ $\min 11080865$

Academic Editors: Lluís Casas and Roberta Di Febo

Received: 18 June 2021

Accepted: 6 August 2021

Published: 11 August 2021

Publisher's Note: MDPI stays neutral with regard to jurisdictional claims in published maps and institutional affiliations.

Copyright: ( $\odot 2021$ by the authors Licensee MDPI, Basel, Switzerland. This article is an open access article distributed under the terms and conditions of the Creative Commons Attribution (CC BY) license (https:// creativecommons.org/licenses/by/ $4.0 /)$.

\section{Introduction}

Garnets are a common group of minerals that undergo complex changes in their composition. The island silicate garnet belongs to the cubic space group, Ia $\overline{3} \mathrm{~d}, \mathrm{Z}=8$ [1], and has the general chemical formula $\mathrm{A}_{3} \mathrm{~B}_{2}\left[\mathrm{SiO}_{4}\right]_{3}$. Position $\mathrm{A}$ is occupied by divalent cations, such as $\mathrm{Mg}^{2+}, \mathrm{Fe}^{2+}, \mathrm{Mn}^{2+}$, and $\mathrm{Ca}^{2+}$, with eight-fold coordination in a dodecahedral site. Position $\mathrm{B}$ is occupied by trivalent cations, such as $\mathrm{Al}^{3+}, \mathrm{Fe}^{3+}$, and $\mathrm{Cr}^{3+}$, with six-fold coordination occupying the octahedral site. $\mathrm{Si}^{4+}$ is a tetravalent cation that can be partially replaced by a small amount of $\mathrm{Ti}^{4+}$, and occupies the tetrahedral position with four-fold coordination [2]. The divalent cations $\mathrm{Mg}^{2+}, \mathrm{Fe}^{2+}$, and $\mathrm{Mn}^{2+}$ have smaller ionic radii than $\mathrm{Ca}^{2+}$, and thus struggle to replace one another. Garnets can hence be divided into two isomeric series: pyralspite and ugrandite.

In gemology, a change in colour that occurs when the source of illumination switches from daylight to incandescent light is called "alexandrite effect". Many gemstones naturally change colour, such as alexandrite [3], diaspore [4,5], Tavernier diamond [6], corundum [7], and garnet [8-11].

A special kind of pyralspite garnet exhibits the alexandrite change in colour. Such garnets appear yellow-green in daylight and purple-red under incandescent light. Colourchanging garnets can be divided into two categories based on their chemical composition: Cr-rich spessartine, and Cr, V-rich pyrope-spessartine solid solutions [12].

Generally the perceived colour of the surface of an object remains constant when the intensity of light and the spectral components of illumination change. The alexandrite effect is a phenomenon of distinctive changes in the colour of a gem when observed under daylight and incandescent light [13]. A change of $20^{\circ}$ in the absolute hue angle is used to identify the alexandrite effect [14].

Tang [15], Cheng [16], and Wang [17] used an X-Rite SP62 portable spectrophotometer to visually measure the colours of gems. Guo et al. $[18,19]$ used Spectrophotometer Colour i5 and the GemDialogue colour chip to quantitatively characterize the colour of jadeite, and 
Tooms et al. [20] used colour matching functions to calculate colour. Kasajima et al. [21,22] used the CIE1931RGB colour matching functions to calculate the colours of the leaves and flowers of the genera Torenia and Cyclamen. Sun et al. [23] used the CIEXYZ colour matching functions to calculate the colour of synthetic Cr-bearing chrysoberyl.

The human retina has three kinds of colour photoreceptors, or cones, that are sensitive to red, green, and blue light. The S cones detect the short wavelength (blue), the $\mathrm{M}$ cones detect the medium wavelength (green), and the L cones detect the long wavelength (red). Xie et al. [24] used the responses of the L, M, and S spectra to calculate the colour of alexandrite.

When irradiated, the spectral stimulation energy is absorbed by photoreceptors of the three cones in our eyes. The cone cells produce different degrees of responses followed by neurophysiological reactions. The International Commission on Illumination (CIE) establishes a series of colour-matching functions through visual experiments. As a proxy for functions of the responsivity of the cones, CIE colour-matching functions are used to represent linear combinations of the average visual response [25].

Matching functions can be used to calculate the energy of light that enters the human eye and produces the sensation of colour. Due to the particularity of colour-changing garnets, this study uses CIE1931XYZ colour-matching functions to quantitatively characterize colour, and investigates the colour of garnets between daylight and incandescent light. The authors also analyze the relationship between the ultraviolet-visible (UV-Vis) spectra and the parameters influencing the perception of colour.

\section{Materials and Methods}

\subsection{Samples}

We collected 10 samples of colour-changing garnets, four oval faceted gems (dimensions from $3 \mathrm{~mm} \times 5 \mathrm{~mm}$ to $4 \mathrm{~mm} \times 5.7 \mathrm{~mm}$ ) and six double-sided polished flats with a thickness of $3 \mathrm{~mm}$. They appeared gray-green under daylight (Figure 1a) and purplish red under incandescent light (Figure 1b), showing a distinct colour-changing effect.

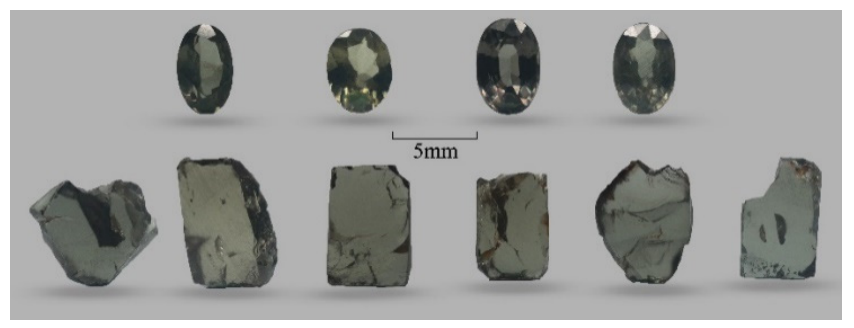

(a)

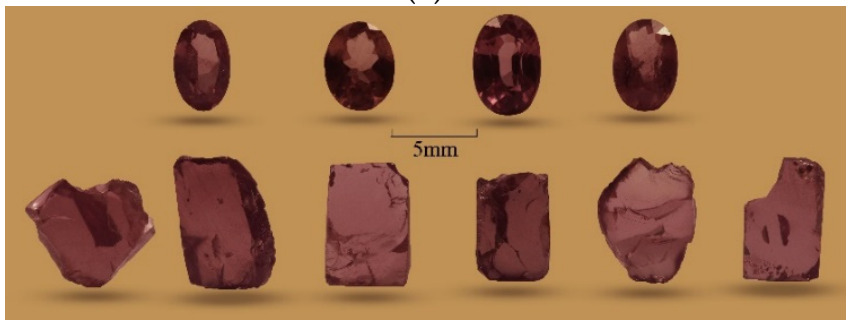

(b)

Figure 1. Photograph of 10 samples of colour-changing garnets. (a) Gray-green under standard D65 light. (b) Purplish red under standard A light.

\subsection{Fourier Transform Infrared (FTIR) Spectroscopy}

The infrared spectra of the samples were measured by a Tensor 27 FTIR spectrometer (Bruker, Germany). The settings of the instrument were: resolution $4 \mathrm{~cm}^{-1}$; scanning range $400-2000 \mathrm{~cm}^{-1}$; run time $30 \mathrm{~s}$ per scan. 


\subsection{UV-Vis Spectroscopy}

The UV-Vis were carried out using a UV-3600 UV-VIS spectrophotometer (Shimadzu, Tokyo, Japan). The test conditions were: wavelength range 200-900 nm; slit width $2 \mathrm{~nm}$; scanning speed high; sampling interval $0.5 \mathrm{~s}$; and the single scanning mode was used.

\subsection{Correcting the UV-Vis Spectra}

Energy is used in three ways when light passes through a sample. A is the total absorbance of the sample measured directly from the spectrophotometer, and includes $A_{c}$ (loss of chromophore light), $A_{r l}$ (loss due to reflection of light on the surface of the gem), and $A_{i s l}$ (loss due to inclusion scattering of light) [12]:

$$
A=A_{c}+A_{r l}+A_{i s l}
$$

The absorption $\left(A_{r l}\right)$ of the incident light reflects along the boundary is related to the refractive index (n) of the sample. The Sellmeier equation is an empirical formula describing the refractive index and wavelength in a specific transparent medium, and is used to determine the dispersion of light in a medium. Different materials have different Sellmeier coefficients. According to research by Wemple and Di Domenico [26,27], and Wemple et al. [28], we obtained the following Sellmeier equation:

$$
\begin{aligned}
& \frac{1}{n^{2}-1}=-\frac{A}{\lambda^{2}}+B \\
& n^{2}=1+\frac{\lambda^{2}}{B \lambda^{2}-A}
\end{aligned}
$$

Medenbach et al. [29] measured the relevant empirical formulae for silicate minerals, and obtained the Sellmeier coefficients of garnets as $A=54 \times 10^{-16} \mathrm{~m}^{2}=5400 \mathrm{~nm}^{2}$, and $B=0.4599$. The relationship between the refractive index of garnet and the wavelength is as follows:

$$
n^{2}=1+\frac{\lambda^{2}}{0.4599 \lambda^{2}-5400}
$$

According to the Lambert-Beer law:

$$
A=\lg \frac{1}{T}=\mathrm{kbc}
$$

where $A$ is absorbance, $T$ is transmissivity, $\mathrm{k}$ is the molar absorbance coefficient, $\mathrm{c}$ is the concentration of the absorbent substance, and $\mathrm{b}$ is the optical path of light.

In the ideal state, when unpolarized light is perpendicular to the incident on the surface of the sample, it has not produced a certain length of the optical path inside the gem. In this case, optical absorption inside the gem can be ignored and the transmittance through the surface of the gem can be expressed as:

$$
T=1-R
$$

Transmissivity can be converted into absorbance according to the Lambert-Beer law:

$$
\begin{gathered}
T=10^{-A}=1-R \\
A=-\lg T=-\lg (1-R) \\
R=\left(\frac{n_{0}-n_{1}}{n_{0}+n_{1}}\right)^{2} \\
A_{r l}=2 A=-2 \lg \left[1-\left(\frac{n_{0}-n_{1}}{n_{0}+n_{1}}\right)^{2}\right]
\end{gathered}
$$


where $R$ is reflectivity, $n_{0}=1$ is the refractive index of light in air, $n_{1}$ is the refractive index of light in the garnet, $T$ is transmissivity, $A$ is the absorbance generated by reflection at a single boundary, and $A_{r l}$ is the absorbance generated by reflection at two boundaries [30,31].

\subsection{CIE1931 XYZ Colour Matching Functions}

In 1931, the CIEXYZ colour system was proposed by the International Commission on Illumination. A colour-matching function, the CIE 1931 standard colorimetric observer spectrum tristimulus value, was obtained by matching the isoenergetic spectrum. The tristimulus values $\mathrm{X}, \mathrm{Y}$, and $\mathrm{Z}$ can be calculated by the colour-matching functions as follows:

$$
\begin{gathered}
\mathrm{X}=\int_{\lambda} k \varphi(\lambda) \bar{x}(\lambda) \mathrm{d} \lambda \approx \sum_{380}^{780} k \varphi(\lambda) \bar{x}(\lambda) \Delta \lambda \\
\mathrm{Y}=\int_{\lambda} k \varphi(\lambda) \bar{y}(\lambda) \mathrm{d} \lambda \approx \sum_{380}^{780} k \varphi(\lambda) \bar{y}(\lambda) \Delta \lambda \\
\mathrm{Z}=\int_{\lambda} k \varphi(\lambda) \bar{z}(\lambda) \mathrm{d} \lambda \approx \sum_{380}^{780} k \varphi(\lambda) \bar{z}(\lambda) \Delta \lambda \\
k=\frac{100}{\int_{\lambda} S(\lambda) \bar{y}(\lambda) \Delta \lambda}
\end{gathered}
$$

In the formula, $S(\lambda)$ is the relative spectral power distribution of the light source. For non-luminous objects, $\varphi(\lambda)$ is the product of the spectral transmittance $T(\lambda)$ and the relative spectral power of the light source $S(\lambda)$, expressed as $T(\lambda) S(\lambda)$, or the product of its spectral reflectance $R(\lambda)$ and the relative spectral power $S(\lambda)$, expressed as $R(\lambda) S(\lambda)$. K is the naturalization coefficient. For non-luminous objects, the value of $Y$ of the selected standard illuminant was adjusted to $100[32,33]$.

\subsection{CIE1976 La*b* Colour System}

The CIE1976 La* $b^{*}$ colour space is the most widely used in the field of colourimetry. The system consists of the axes of plane chromaticity $a^{*}$ and $b^{*}$, and the vertical axis $L^{*}$. $+a^{*}$ represents red, $-a^{*}$ represents green; $+b^{*}$ represents yellow, and $-b^{*}$ represents blue. The chroma $\mathrm{C}^{*}$ and hue angle $\mathrm{h}\left({ }^{\circ}\right)$ can be calculated from the chromaticities $\mathrm{a}^{*}$ and $\mathrm{b}^{*}[32,34]$ :

$$
\begin{aligned}
C^{*} & =\sqrt{a^{* 2}+b^{* 2}} \\
h & =\arctan \frac{b^{*}}{a^{*}}
\end{aligned}
$$

To calculate the colour difference of garnets under different sources of illumination, we chose the $\operatorname{CIE~} \operatorname{Lab}\left(\Delta \mathrm{E}^{*} \mathrm{ab}\right)$ colour difference formula:

$$
\Delta E_{a b}^{*}=\sqrt{\left(\Delta L^{*}\right)^{2}+\left(\Delta a^{*}\right)^{2}+\left(\Delta b^{*}\right)^{2}}
$$

where $\Delta a^{*}=a_{D 65}^{*}-a_{A}^{*}, \Delta b^{*}=b_{D 65}^{*}-b_{A}^{*}$, and $\Delta L^{*}=L_{D 65}^{*}-L_{A}^{*}$, and $\Delta \mathrm{h}\left(^{\circ}\right)$ is the hue angle difference under different sources of illumination:

$$
\Delta h=h_{D 65}-h_{A}
$$

where $\Delta C^{*}$ is the chroma difference under different sources of illumination:

$$
\Delta C^{*}=C_{D 65}^{*}-C_{A}^{*}
$$




\subsection{Colour Space Conversion}

To easily observe the colour distribution, the colour tristimulus values in CIEXYZ were non-linearly converted to obtain the colour parameters $\mathrm{L}^{*}, \mathrm{a}^{*}$ and $\mathrm{b}^{*}$ in the CIE1976 $L^{*} a^{*} b^{*}$ colour space system $[32,34]$. The formula for conversion is as follows:

$$
\begin{gathered}
L^{*}=116\left(\frac{X}{X_{n}}\right)^{\frac{1}{3}}-16 \\
a^{*}=500\left[\left(\frac{X}{X_{n}}\right)^{\frac{1}{3}}-\left(\frac{Y}{Y_{n}}\right)^{\frac{1}{3}}\right] \\
b^{*}=200\left[\left(\frac{Y}{Y_{n}}\right)^{\frac{1}{3}}-\left(\frac{Z}{Z_{n}}\right)^{\frac{1}{3}}\right]
\end{gathered}
$$

For the D65 light source, $X_{n}=95.04, Y_{n}=100$, and $Z_{n}=108.88$. For light source A, $X_{n}=109.85, Y_{n}=100$, and $Z_{n}=35.58 . X_{n}, Y_{n}$, and $Z_{n}$ are colorimetric data obtained from the CIE 1931 standard colorimetric observer $\left(2^{\circ}\right)$ [35].

\section{Results}

\subsection{Infrared Spectral Characteristics of Colour-Changing Garnet}

The infrared spectra of the garnets are shown in Figure 2. Vibrations inside the $\left[\mathrm{SiO}_{4}\right]^{4-}$ group produced the $\mathrm{A}-\mathrm{G}$ absorption bands above $500 \mathrm{~cm}^{-1}$. The A-D absorption zone (bands in the range $800-1100 \mathrm{~cm}^{-1}$ ) is due to the antisymmetric stretching vibration of the $\left[\mathrm{SiO}_{4}\right]$ tetrahedron, and is caused by the splitting of the $v_{3}$ triplet degenerate inside $\left[\mathrm{SiO}_{4}\right]$. The E- $\mathrm{G}$ absorption zone relates to the antisymmetric bending vibration of $\left[\mathrm{SiO}_{4}\right]$, and shows a peak at $500-700 \mathrm{~cm}^{-1}$ due to double-degeneracy splitting of $v_{2}$ or tripledegeneracy splitting of $v_{4}$. External vibrations, namely lattice vibrations, produce the $\mathrm{H}-\mathrm{K}$ absorption band, below $500 \mathrm{~cm}^{-1}$. The $\mathrm{H}-\mathrm{I}$ absorption bands within this are related to vibrations of the trivalent cation $\left(\mathrm{B}^{3+}\right)$, and the J-K absorption band to vibrations of the divalent cation $\left(\mathrm{A}^{2+}\right)[36,37]$. In the lattice of the garnets, the volume of the octahedral $\left[\mathrm{BO}_{6}\right]$ group is higher than that of $\left[\mathrm{SiO}_{4}\right]$, and the $\mathrm{B}-\mathrm{O}$ bond is weaker than the $\mathrm{Si}-\mathrm{O}$ bond. This is reflected in the decrease in the bond force constant $\mathrm{K}$ in the infrared spectra, and leads to the absorption band appearing in the low-frequency region [36].

Most garnets have $\mathrm{E}$ bands in the $600-650 \mathrm{~cm}^{-1}$ range. The intensity of band $\mathrm{E}$ is related to the ratio $\mathrm{Pyr} / \mathrm{Alm}$, and it decreases with the increase of the composition content of pyrope. Band $\mathrm{E}$ is stronger in spessartine, but the band $\mathrm{G}$ is weak or even missing [36]. When irradiated by infrared light, the sample selectively absorbs wavelengths that match its vibrational frequency and produce energy-level transitions. The energy required for vibration-induced transition depends on the reduced mass of atoms at both ends of the bond and its force constant. According to the vibration equation $v=\frac{1}{2 \Pi} \sqrt{\frac{K}{m}}$, when the group is fixed, its vibrational frequency is proportional to the chemical bond force constant $\mathrm{K}$. That is, with the increase in the radius of the cation, electronegativity decreases, as does the bond energy between the metal cation and the oxygen ion. This reduces the vibrational frequency of the chemical bond, and the band frequency shifts to the region of low frequency [38]. In the garnets considered, the radius of $\mathrm{Mn}^{2+}$ is larger than those of $\mathrm{Fe}^{2+}$ and $\mathrm{Mg}^{2+}\left(\mathrm{Mn}^{2+}>\mathrm{Fe}^{2+}>\mathrm{Mg}^{2+}\right)$. As the radius increases, the bond force constant decreases and the band frequency shifts to the red region. The infrared spectrum of the colour-changing garnet is located between spessartine and pyrope, and belongs to the solid solution of pyrope-spessartine garnets. 


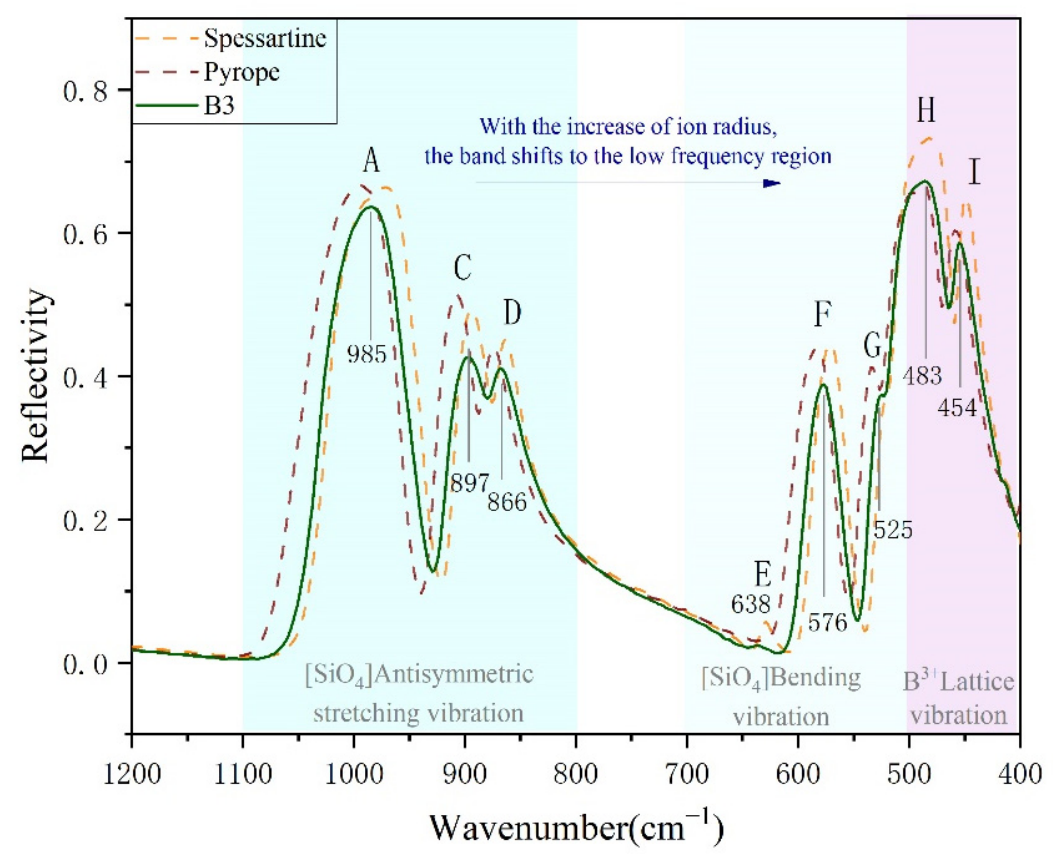

Figure 2. FTIR spectra of the colour-changing garnet (the spectral line data of pyrope and spessartine in the figure derived from subspecies of garnets identified by EPMA).

\subsection{UV-Vis Spectral Characteristics of Colour-Changing Garnet}

The crystal structure of garnet (Figure 3 ) is composed of an isolated $\left[\mathrm{SiO}_{4}\right]$ tetrahedron bound to an $\left[\mathrm{AlO}_{6}\right]$ octahedron in which some $\mathrm{Al}^{3+}$ ions are replaced by $\mathrm{Fe}^{3+}$ and $\mathrm{Cr}^{3+}$. Some large dodecahedral voids are formed between the tetrahedron and the octahedron, the top of each corner is occupied by $\mathrm{O}^{2-}$ ions, and the center contained divalent metal ions. Each divalent ion is surrounded by eight oxygen, and have eight-fold coordination. The optical absorption spectra and colour of the garnet are determined by transition metal ions that occupied site $\mathrm{A}$ of the dodecahedron $\left(\left[\mathrm{AO}_{8}\right]\right)$ and site $\mathrm{B}$ of the octahedron $\left(\left[\mathrm{BO}_{6}\right]\right)$. On site $\mathrm{A}, \mathrm{Mn}^{2+}$ and $\mathrm{Fe}^{2+}$ induce optical absorption bands in the visible spectrum, while on site $\mathrm{B}, \mathrm{Fe}^{3+}, \mathrm{Mn}^{3+}, \mathrm{V}^{3+}$, and $\mathrm{Cr}^{3+}$ are responsible for optical transitions [39].
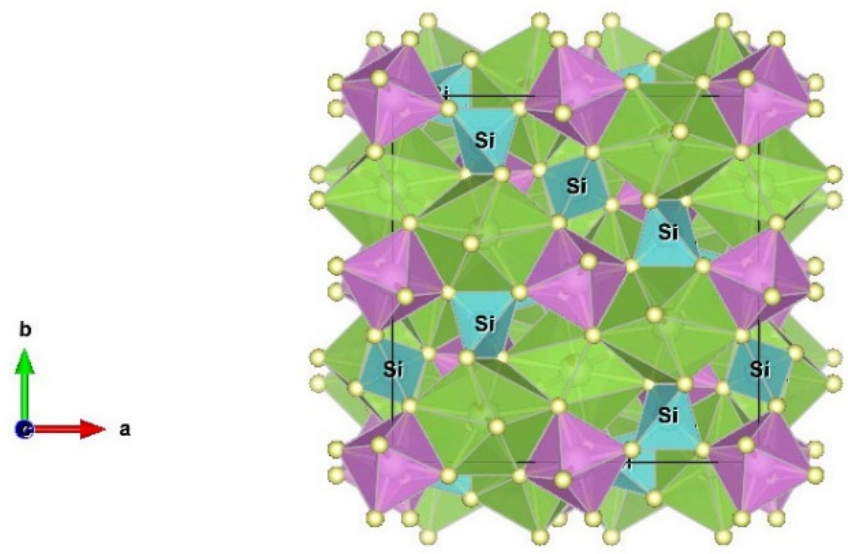

Figure 3. Crystal structure of the garnet (Novak and Gibbs (1971) [2]).

The UV-visible spectrum of the colour-changing garnet is shown in Figure 4. Four weak absorption peaks are present in the blue-green region. The absorption at $525 \mathrm{~nm}$ and $460 \mathrm{~nm}$ correspond to $\mathrm{Mn}^{2+}$ and the spin-forbidden transitions of $\mathrm{Fe}^{2+}\left({ }^{5} \mathrm{Eg}^{-}{ }^{3} \mathrm{~T}_{1 \mathrm{~g}}\right.$ and $\left.{ }^{5} \mathrm{Eg}_{\mathrm{g}}-{ }^{3} \mathrm{E}_{1 \mathrm{~g}}\right)$. The absorption at $506 \mathrm{~nm}$ corresponds to spin-forbidden transitions of $\mathrm{Fe}^{2+}$, $484 \mathrm{~nm}$ corresponds to $\mathrm{Mn}^{2+}$, and $424 \mathrm{~nm}$ corresponds to $\mathrm{Mn}^{2+}$ and six-fold spin-forbidden 
transitions of $\mathrm{Fe}^{3+}\left({ }^{6} \mathrm{~A}_{1 \mathrm{~g}-}{ }^{4} \mathrm{~A}_{1 \mathrm{~g}}\right.$ and $\left.{ }^{6} \mathrm{~A}_{1 \mathrm{~g}}{ }^{4} \mathrm{E}_{\mathrm{g}}\right)$. The three absorption bands of $\mathrm{Fe}^{3+}$ in the yellow-green area showed the typical absorption pattern of the "iron-aluminum window" in the spectroscope [40-44].

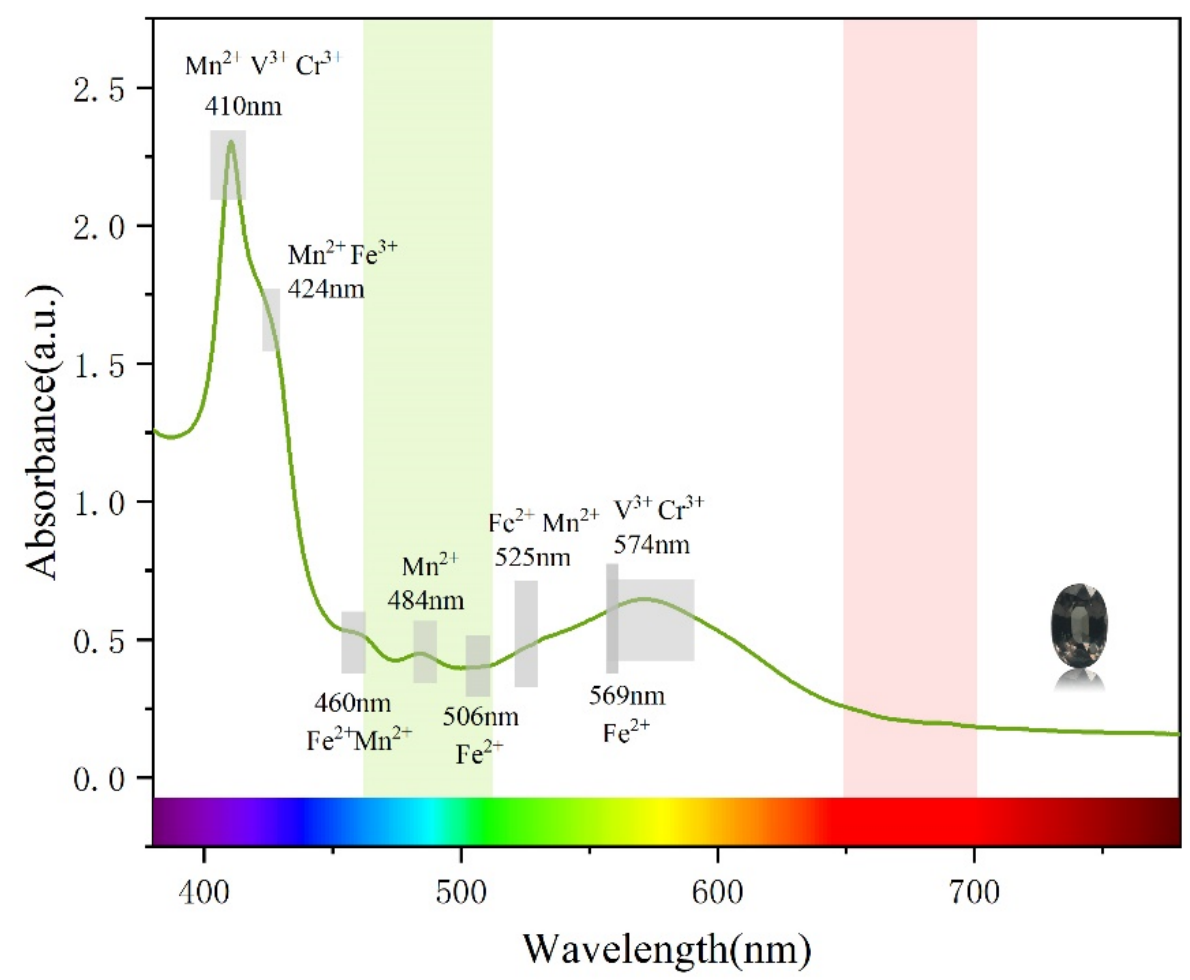

Figure 4. UV-Vis specturm of the colour-changing garnet sample B3 (Two transmission windows appear at 460-510 and 650-700 $\mathrm{nm}$ ).

Two strong absorption bands are centered at $410 \mathrm{~nm}$ and $574 \mathrm{~nm}$ in the blue-purple and orange-yellow region, respectively. The absorption at these two positions are related to the $\mathrm{d}-\mathrm{d}$ electron transition of $\mathrm{V}^{3+}$, and are assigned to the spin-allowed transitions ${ }^{3} \mathrm{~T}_{1 \mathrm{~g}}(3 \mathrm{~F}) \rightarrow{ }^{3} \mathrm{~T}_{2 \mathrm{~g}}(3 \mathrm{~F})$ and ${ }^{3} \mathrm{~T}_{1 \mathrm{~g}}(3 \mathrm{~F}) \rightarrow{ }^{3} \mathrm{~T}_{1 \mathrm{~g}}(3 \mathrm{P})$ [45], respectively. $\mathrm{Cr}^{3+}$ mainly occupies site $\mathrm{B}$ in the garnet crystal. With the action of the octahedral field, the $\mathrm{d}$ orbital undergo energylevel splitting, and electrons in the low-energy d orbital absorb energy and transmit to the high-energy $\mathrm{d}$ orbital. The ${ }^{4} \mathrm{~A}_{2 \mathrm{~g}} \rightarrow{ }^{4} \mathrm{~T}_{2 \mathrm{~g}}$ transition leads to absorption in the blue and purple region, and the ${ }^{4} \mathrm{~A}_{2 \mathrm{~g}} \rightarrow{ }^{4} \mathrm{~T}_{1 \mathrm{~g}}$ transition leads to absorption in the orange and yellow region of visible light [46]. Two transmission windows appear at 460-510 and 650-700 nm that transmit blue-green and red light, respectively. When the transmittance of the two regions is almost the same, the colour of the gem is determined by the external light source.

\subsection{Correcting the Absorbance of UV-Vis Spectra}

Accurate visible spectroscopic measurements rely on correctly identifying the spectral baseline. A relatively clean place in the interior was selected for the UV-Vis spectrum test to eliminate loss due to the scattering of light caused by inclusion. Sample B3 is used as an example. The spectrum after baseline correction by the Sellmeier equation is shown in Figure 5. The green line represents the original spectrum, the yellow line the absorption spectrum after baseline correction, and the gray line, which is approximately a straight line, represents absorption caused by boundary reflection. 


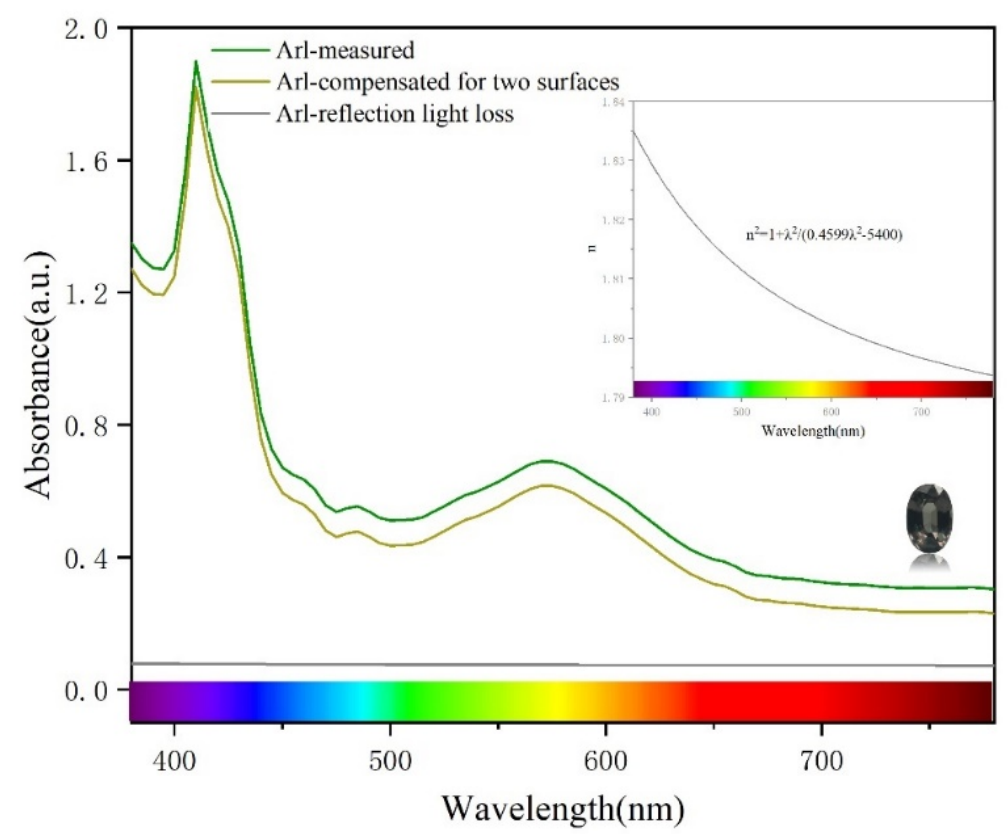

Figure 5. Corrected UV-Vis spectra of the colour-changing garnet sample B3, and relationship between refractive index and wavelength.

\subsection{Colour Calculation by CIE1931 XYZ Colour Matching Functions}

The "alexandrite effect" originally referred to an observed change in colour in the variety of the mineral chrysoberyl (from green under daylight to reddish-purple under incandescent light) [47]. Typically, the light sources are represented in colourimetry by standardized illuminants. The CIE Illuminant D65 represents average daylight with a correlated colour temperature of approximately $6504 \mathrm{~K}$, and the CIE Illuminant A represents incandescent light with a correlated colour temperature of approximately $2856 \mathrm{~K}$. Their spectral power distributions are shown in Figure $6 \mathrm{a}, \mathrm{b}$.

The colour of transparent gems can be calculated according to the spectra of the light source and the transmission spectra of the gems. The integral of the curve of spectral response corresponds to the signal emitted by cones of the human eye. The spectra of responses of the cones, the illuminants, and the transmittance of the stones are combined to determine the perception. Figure 6 shows spectral responses of the CIEXYZ colourmatching functions. In Figure $6 c, d$, the products of the illuminant spectra and the spectra of the colour matching functions are plotted. The integrals of these curves correspond to signals sent by the cones, and their values are marked (D65: $X=95.04, Y=100, Z=108.87$; $A: X=109.85, Y=100, Z=35.58)$. These are approximately the colours of white objects perceived under the two light sources. The spectral response curve obtained in Figure $6 c, d$ is multiplied by the transmission spectra $(T(\lambda))$ of garnet to obtain the colour of the gems under the D65 and A light sources by integrating the response curve (Figure 6e,f) (data on the CIEXYZ colour-matching functions were obtained from the official CIE website [48]).

In light of the UV-Vis spectrum of the colour-changing garnet, it is clear that the gem absorbs the blue-violet light and orange-yellow light, and allows equal transmittance of red and green light. The colour of the gem is thus determined by the external light source. Daylight has a higher spectral energy distribution in the blue-green region. When light is incident on the gem, Figure 6e shows that the spectral curve has the strongest response in the blue-green region. The sample appears green under daylight $(\mathrm{X}=34.58, \mathrm{Y}=36.69$, $\mathrm{Z}=32.19$ ). 

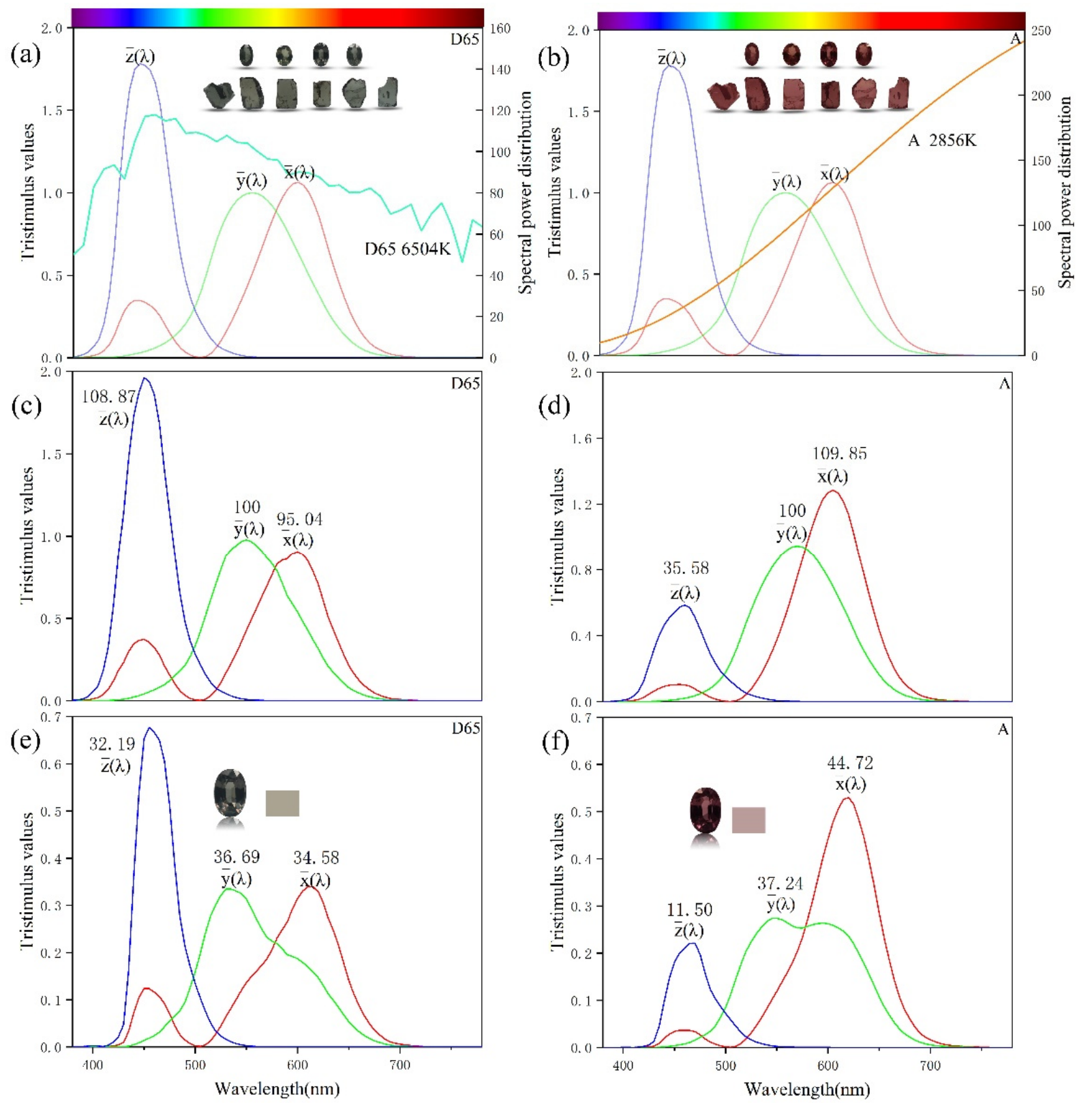

Figure 6. Analysis and explanation of the alexandrite effect (with sample B3 as an example). The spectral response curves of the CIE1931 XYZ colour matching functions are shown. (a) The spectral power distribution of the CIE D65 representing daylight (colour temperature, $6504 \mathrm{~K}$ ). (b) The spectral power distribution of the incandescent light CIE A (colour temperature, $2856 \mathrm{~K}$ ). (c) Response curves of spectra of D65 obtained from the colour-matching functions. (d) Response curves of spectra of A obtained from the colour-matching functions. (e) Response curves of the colour matching functions of the colour-changing garnet under D65. (f) Response curves of the colour matching functions of the colour-changing garnet under A. The tristimulus values and the simulated colour obtained by the integration of the curve are shown in the figure.

Incandescent light has a higher spectral energy distribution in the red zone, causing the sample to transmit more components of red that obscured the green light. Figure $6 f$ shows that the spectral curve has the strongest response in the red zone; red light was dominant, and is superimposed with a small amount of the transmitted purple light. The garnet thus appears purplish-red $(X=44.72, Y=37.24, Z=11.50)$.

The values of the colour tristimulus XYZ were non-linearly converted into the parameters of colour in the CIE1976 L*a*b* colour space, and the chroma value $C^{*}$ and hue angle 
$\mathrm{h}\left({ }^{\circ}\right)$ of the colour under the D65 and A light sources were calculated. The results are shown in Table 1. Under D65 light, the average colour lightness $\left(\overline{L^{*}}\right)$ is 63.07 , the chroma average $\left(\overline{C^{*}}\right)$ is 12.37 , and the average hue angle $(\bar{h})$ is $97.92^{\circ}$, representing green. Under light source A, the average colour lightness $\left(\overline{L^{*}}\right)$ is 63.53 , the chroma average $\left(\overline{C^{*}}\right)$ is 13.72 , and the average hue angle $(\bar{h})$ is $42.56^{\circ}$, representing red.

Table 1. Colour parameters, hue angle, chroma and colour difference between the light sources in CIE $1976 \mathrm{La}^{*} \mathrm{~b}^{*}$ colour space (the original data is presented in the supplementary materials).

\begin{tabular}{|c|c|c|c|c|c|c|c|c|c|}
\hline \multirow{2}{*}{ Sample } & \multicolumn{3}{|c|}{ D65 } & \multicolumn{3}{|c|}{$\mathbf{A}$} & \multirow{2}{*}{$\Delta \mathbf{h}\left({ }^{\circ}\right)$} & \multirow{2}{*}{$\Delta \mathrm{C}^{*}$} & \multirow{2}{*}{$\Delta E^{*} a b$} \\
\hline & $\mathbf{L}^{*}$ & $C^{*}$ & $h\left({ }^{\circ}\right)$ & $\mathbf{L}^{*}$ & $C^{*}$ & $h\left({ }^{\circ}\right)$ & & & \\
\hline B1 & 62.04 & 11.79 & 104.64 & 62.34 & 10.84 & 50.71 & 53.93 & -0.94 & 10.30 \\
\hline B2 & 68.01 & 16.69 & 105.18 & 68.44 & 14.22 & 72.22 & 32.97 & -2.48 & 9.10 \\
\hline B3 & 67.04 & 10.00 & 95.70 & 67.46 & 12.73 & 31.43 & 64.27 & 2.73 & 12.31 \\
\hline B4 & 57.94 & 10.80 & 107.80 & 58.16 & 9.62 & 48.67 & 59.13 & -1.18 & 10.13 \\
\hline B5 & 42.70 & 9.84 & 85.22 & 43.30 & 14.14 & 31.26 & 53.96 & 4.30 & 11.60 \\
\hline B6 & 62.11 & 14.15 & 90.54 & 62.83 & 17.92 & 36.92 & 53.62 & 3.77 & 14.87 \\
\hline B7 & 68.87 & 12.46 & 96.37 & 69.38 & 14.54 & 38.06 & 58.31 & 2.08 & 13.29 \\
\hline B8 & 65.70 & 14.07 & 97.08 & 66.26 & 15.08 & 45.18 & 51.90 & 1.01 & 12.80 \\
\hline B9 & 68.95 & 12.19 & 97.75 & 69.42 & 14.41 & 35.85 & 61.89 & 2.22 & 13.82 \\
\hline B10 & 67.29 & 11.70 & 98.91 & 67.71 & 13.71 & 35.34 & 63.57 & 2.02 & 13.50 \\
\hline
\end{tabular}

In the CIE1976 L*a*b* colour space, the difference in hue angle is often used to quantitatively evaluate the intensity of colour-changing effect. When the difference in the hue angle is greater than $20^{\circ}$, prominent changes in colour can be observed [14]. The 10 samples selected in this study exhibit significant change in colour with hue angle difference greater than $20^{\circ}$. Figure 7 shows the simulated colour block calculated by the colour matching functions. It had a high degree of reduction to the real colour of the sample.

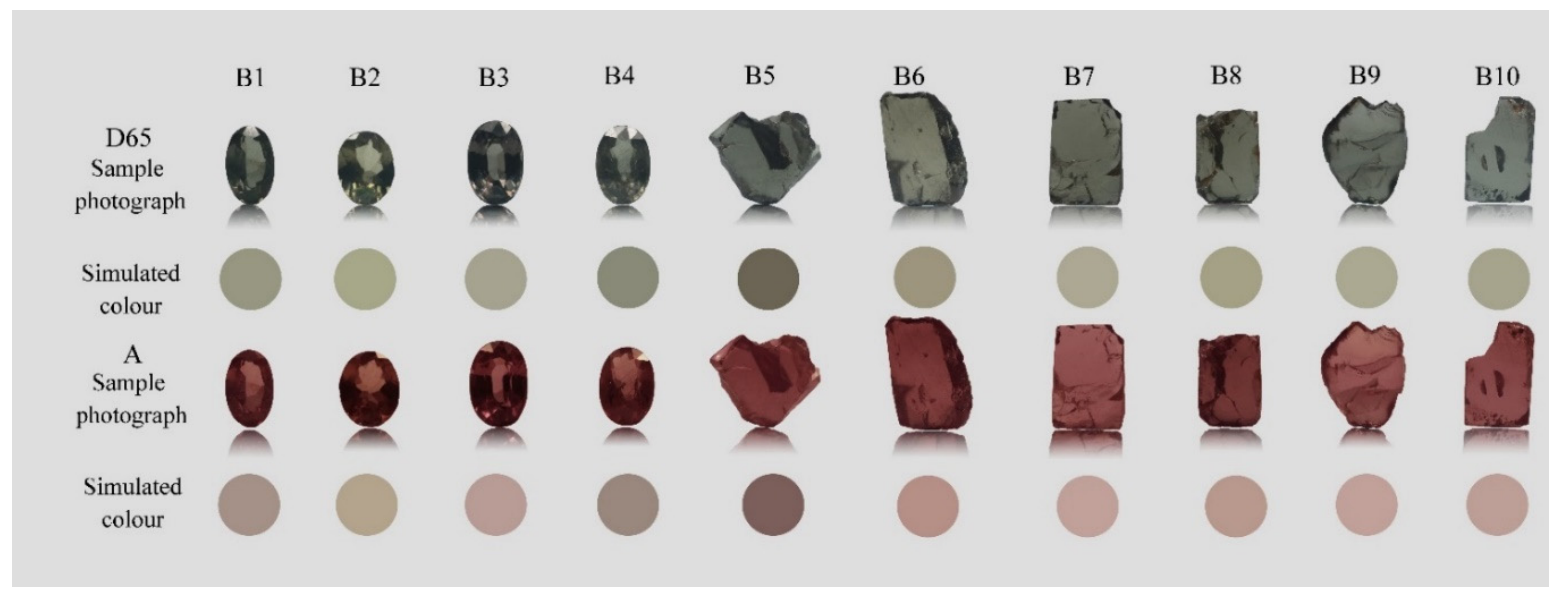

Figure 7. Fashioned gems and the corresponding simulated colours calculated by using the colour matching functions.

\section{Discussion}

\subsection{Effect of Standard Light Source on Appearance of Colour-Changing Garnet}

An one-way analysis of variance (ANOVA) of the parameters influencing colour is conducted under the D65 and A light sources, and the results are shown in Table 2. The different standard light sources have no significant effect on the lightness $L^{*}$ and chroma $\mathrm{C}^{*}$ of the colour-changing garnet $(p>0.05)$, but have a significant effect on the colorimetric coordinates $\mathrm{a}^{*}$ and $\mathrm{b}^{*}$ as well as the hue angle $\mathrm{h}\left({ }^{\circ}\right)(p<0.05)$. 
Table 2. ANOVA results for the colour parameters.

\begin{tabular}{ccccc}
\hline Colour Parameters & df & Mean Square & F & $p$ \\
\hline $\mathrm{L}^{*}$ & 1 & 1.070 & 0.017 & 0.898 \\
$\mathrm{a}^{*}$ & 1 & 688.632 & 116.762 & 0.000 \\
$\mathrm{~b}^{*}$ & 1 & 50.444 & 11.696 & 0.003 \\
$\mathrm{C}^{*}$ & 1 & 9.146 & 1.888 & 0.186 \\
$\mathrm{~h}\left(^{\circ}\right)$ & 1 & $15,320.707$ & 152.244 & 0.000 \\
\hline
\end{tabular}

Figure 8 shows a comparison of the colour parameters under the D65 and A light sources. The results show that the lightness of the garnet under A is slightly higher than that under D65, and most of the samples exhibit higher chroma values under A. When the light source is changed from D65 to A, the colorimetric coordinate $\mathrm{a}^{*}$ changes from negative to positive, that is, from green to red; the colorimetric coordinate $\mathrm{b}^{*}$ decreases, and the concentration of yellow decreases. Samples with higher colorimetric coordinates $\mathrm{a}^{*}$ and $b^{*}$ in the light source D65 are also higher under light source A.

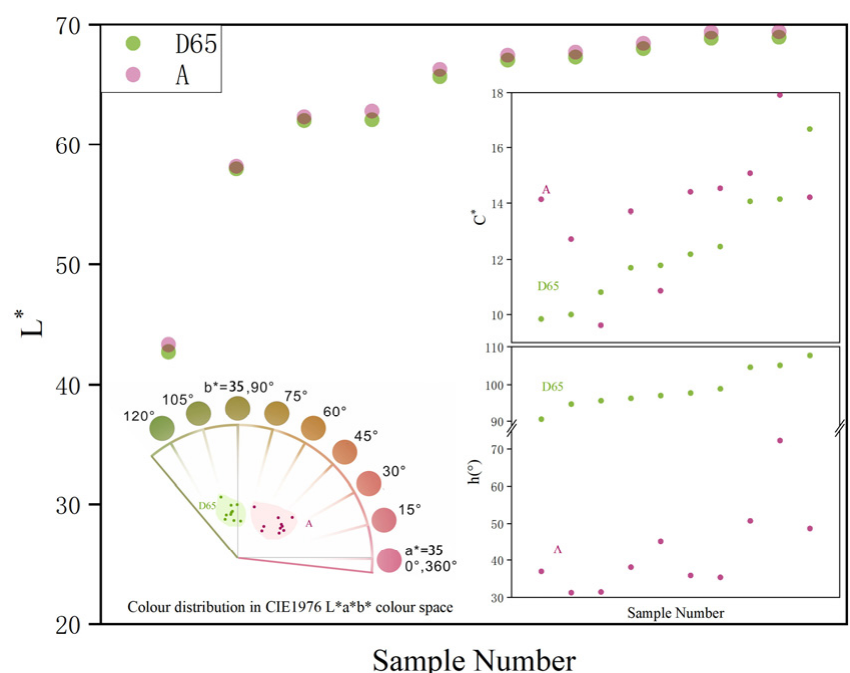

(a)

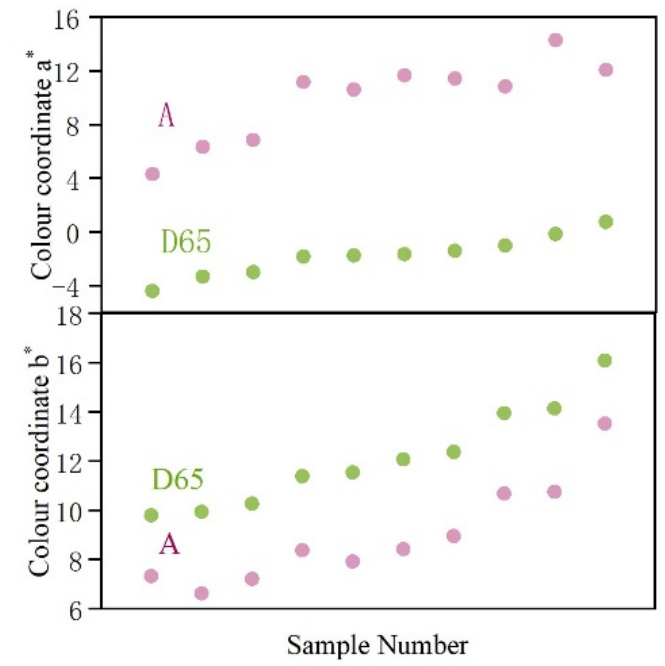

(b)

Figure 8. Comparison of colour parameters under two kinds of standard light sources. (a) Comparison of lightness $\mathrm{L}^{*}$, chroma $\mathrm{C}^{*}$, and hue angle $\mathrm{h}\left(^{\circ}\right) ;(\mathbf{b})$ Comparison of colorimetric coordinates $\mathrm{a}^{*}$ and $\mathrm{b}^{*}$.

\subsection{Effect of UV-Vis Absorbance Peak Area on Colorimetric Coordinate $a^{*}$ and Hue Angle $h\left(^{\circ}\right)$}

The strong absorption band at $574 \mathrm{~nm}$ in the UV-Vis spectrum plays a decisive role in determining the colour of a colour-changing garnet [39]. The first derivative of the UV-Vis spectrum is calculated, and points with a zero derivative near $510 \mathrm{~nm}$ and $680 \mathrm{~nm}$ are selected as starting and ending points, respectively, for calculating the peak area of absorption at $574 \mathrm{~nm}$ (Figure 9).

The results show that the colorimetric coordinate $\mathrm{a}^{*}$ is positively correlated with the area of the peak at $574 \mathrm{~nm}\left(\mathrm{D} 65: R^{2}=0.909 ; \mathrm{A}: R^{2}=0.821\right.$, Figure 10a). With the increase in the area, the colorimetric coordinate $\mathrm{a}^{*}$ gradually increases, that is, the concentration of green decreases under the D65 light source, and the concentration of red increases under the A light source. 


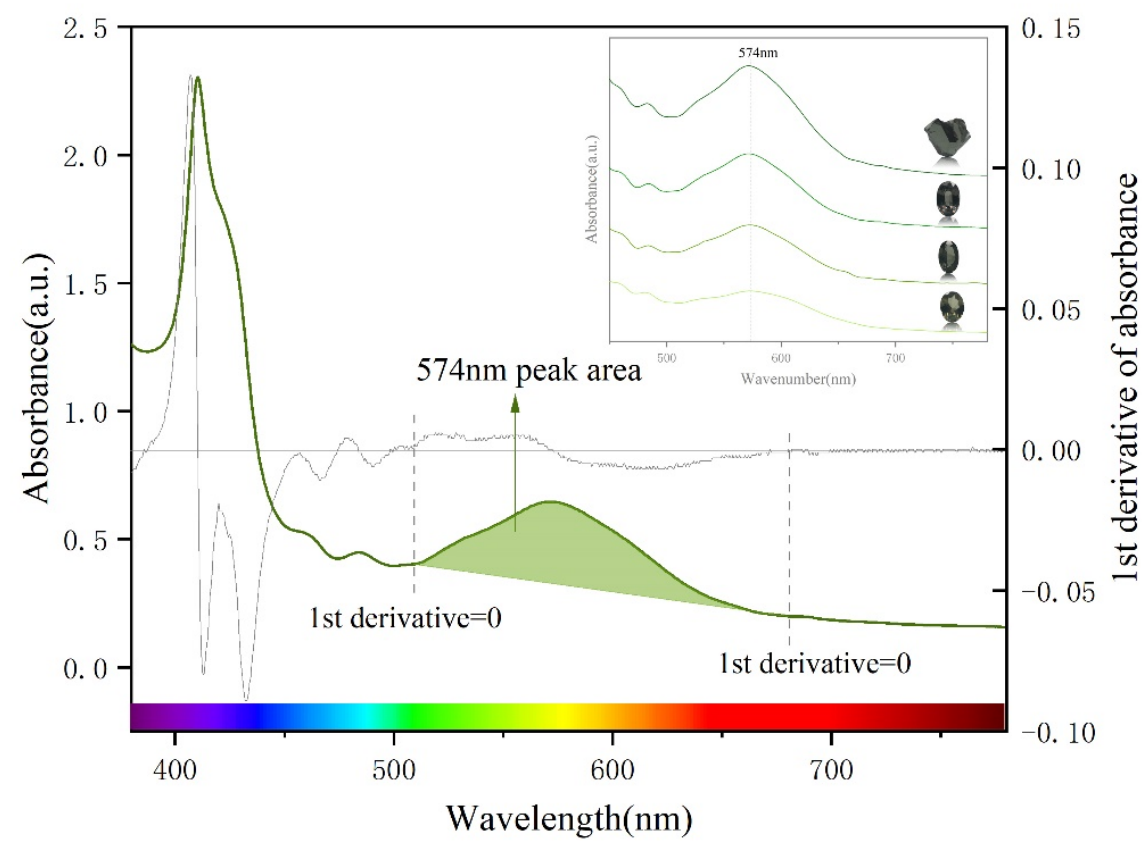

Figure 9. The area of the absorption peak at $574 \mathrm{~nm}$ affects the colour-changing garnet. Taking sample B3 as an example, the gray line is the first derivative curve of its UV-Vis spectrum, and the point where the first derivative is equal to zero is selected as the starting and ending points of the range at $574 \mathrm{~nm}$ absorption peak.

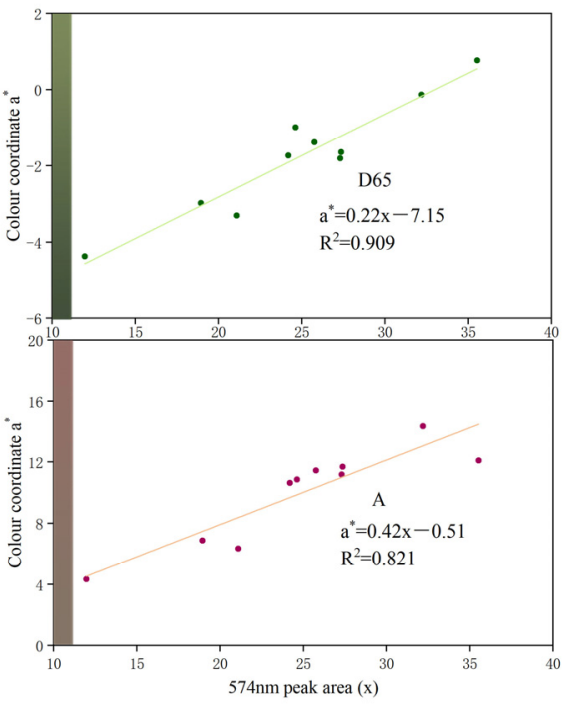

(a)

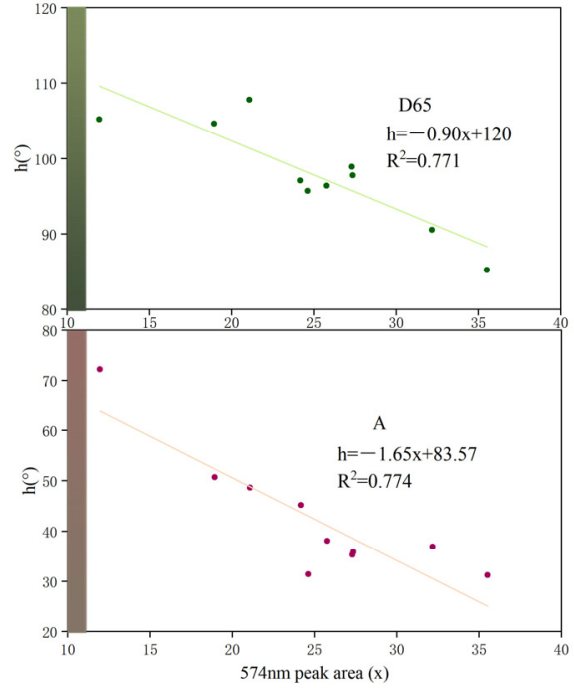

(b)

Figure 10. The colorimetric coordinate $\mathrm{a}^{*}$ and the hue angle $\mathrm{h}\left({ }^{\circ}\right)$ are related to the peak area of absorption at $574 \mathrm{~nm}$. Under the D65 and A light sources, $\mathrm{a}^{*}$ is positively correlated with the area of the absorption peak (a) whereas $\mathrm{h}$ is negatively correlated with it at $574 \mathrm{~nm}(\mathbf{b})$.

A negative correlation is noted between the hue angle $\mathrm{h}\left({ }^{\circ}\right)$ and the peak area at $574 \mathrm{~nm}$ (D65: $R^{2}=0.771 ; A: R^{2}=0.774$, Figure 10b). With the increase in the peak area, the hue angle $\mathrm{h}\left({ }^{\circ}\right)$ decreases gradually. Under the D65 light source, $\mathrm{h}\left({ }^{\circ}\right)$ changes from $107.80^{\circ}$ to $85.22^{\circ}$, and the colour of the garnet changes from green to yellow-green. Under light source $\mathrm{A}, \mathrm{h}\left({ }^{\circ}\right)$ changes from $72.22^{\circ}$ to $31.26^{\circ}$, and the colour of the garnet changes from orange-red to red and purplish-red. 


\subsection{Effect of UV-Vis Absorbance Peak Area on Chroma Difference $\Delta C^{*}$ and Colour Difference $\Delta E_{a b}^{*}$}

The calculated colour of the garnet is plotted in the CIE1976 La*b* colour space (Figure 11). In three-dimensional space, the line connecting the points under the two light sources signifies the Euclidean distance, which represents the colour difference $\left(\Delta E_{a b}^{*}\right)$ between the light sources. The colour of the garnets changes from green under D65 light source to orange-red and purple-red under A light source, with a change in the hue angle greater than $20^{\circ}$. When changing the light source from D65 to A, difference in the hue angle $\Delta \mathrm{h}\left({ }^{\circ}\right)$ varies from $32.97^{\circ}$ to $64.27^{\circ}$, the difference in chroma $\Delta \mathrm{C}^{*}$ varies from -2.48 to 4.30 , and the colour difference $\Delta E_{a b}^{*}$ varies from 9.10 to 14.87 . When the colour difference value $\Delta E_{a b}^{*}$ is greater than 6, the difference between colour is unacceptable in visual perception, and obvious color change can be observed visually [32].

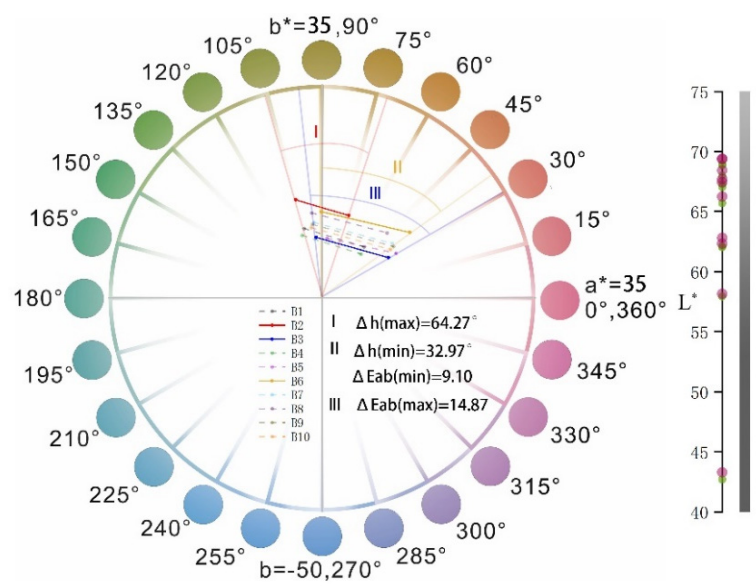

Figure 11. The differences in chroma and colour under the D65 and A light sources in CIE1976 L*a* $\mathrm{b}^{*}$ colour space.

To explore factors affecting colour when the light source is changed, the relationship between the area of peak absorption UV-Vis and colour parameters is analyzed. The differences in the chroma and colour of the garnet between the light sources are positively correlated with the absorption peak at $574 \mathrm{~nm}\left(\mathrm{R}^{2}\right.$ is 0.885 and 0.911 , respectively; Figure 12), exhibiting good fitting. The results show that with the increase in the area of peak absorption at $574 \mathrm{~nm}$, the differences in chroma and colour under D65 and A are large. This leads to a noticeable change in colour.

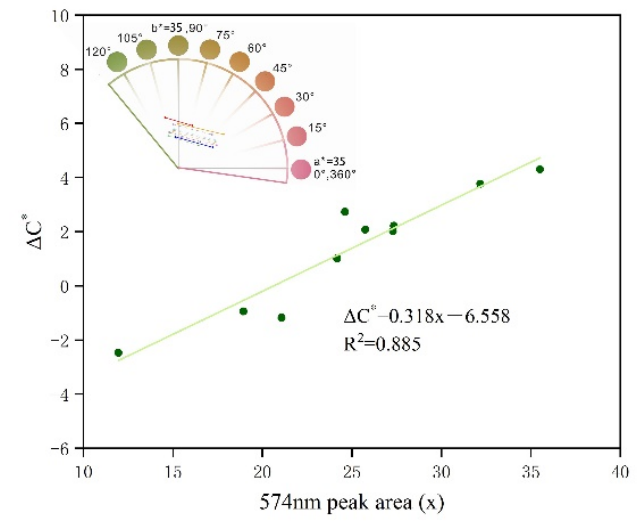

(a)

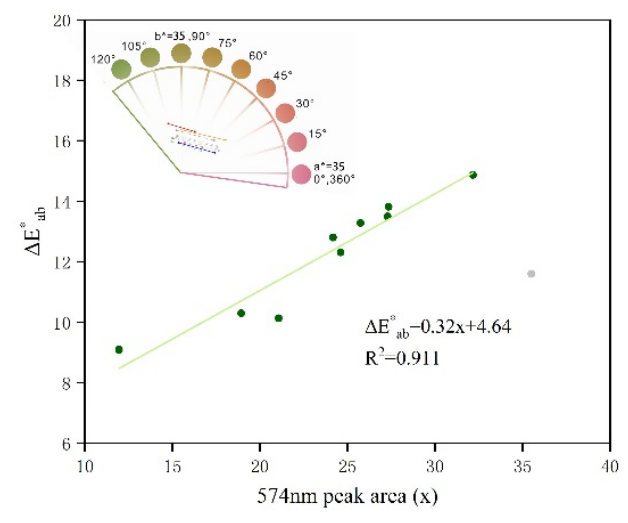

(b)

Figure 12. Chroma difference $\Delta \mathrm{C}^{*}(\mathbf{a})$ and colour difference $\Delta \mathrm{E}_{\mathrm{ab}}^{*}(\mathbf{b})$ are positively correlated with the area of the absorption peak at $574 \mathrm{~nm}$. 


\section{Conclusions}

The infrared spectra show that the colour-changing garnets described in this paper belong to the solid solution of pyrope-spessartine garnets type. There are two zones of transmittance in the red region, $650-700 \mathrm{~nm}$, and the blue-green region, $460-510 \mathrm{~nm}$, of the UV-Vis spectra of a colour-changing garnet. They allow the same amount of light to pass through, because of which the colour of the gem is determined by the external light source. Daylight (D65) has a higher spectral energy distribution in the blue-green zone than incandescent light, which causes the garnet to appear green $\left(\overline{L^{*}}=63.07, \bar{C}^{*}=12.37, \bar{h}=97.92^{\circ}\right)$. Incandescent light (A) has higher spectral energy distribution in the red zone, which causes the colour-changing garnet to appear purple-red $\left(\overline{L^{*}}=63.53, \overline{C^{*}}=13.72, \bar{h}=42.56^{\circ}\right)$.

The absorption bands of $\mathrm{Cr}^{3+}$ and $\mathrm{V}^{3+}$ at $574 \mathrm{~nm}$ in the UV-Vis spectrum are the main cause of the change in colour. With the increase in the area of peak absorption, the colour of the garnet changes from green to yellow green under daylight (D65), and from orange red to purple-red under incandescent light (A). The colour difference and chroma difference also increases with the peak area, rendering prominent changes in the colour of the garnet more likely.

Supplementary Materials: The following are available online at https://www.mdpi.com/article/ 10.3390/min11080865/s1, Table S1: colour parameters, hue angle, chroma and colour difference between the light sources in CIE $1976 \mathrm{La}^{*} \mathrm{~b}^{*}$ colour space.

Author Contributions: Conceptualization, Y.Q. and Y.G.; Methodology, Y.Q. and Y.G.; Validation, Y.Q. and Y.G.; Formal analysis, Y.Q.; Investigation, Y.Q. and Y.G.; Resources, Y.Q. and Y.G.; Data Curation, Y.Q.; Writing—original draft preparation, Y.Q.; Writing—review and editing, Y.G.; Visualization, Y.Q.; Supervision, Y.G.; Project administration, Y.G. Both authors have read and agreed to the published version of the manuscript.

Funding: This research received no external funding.

Data Availability Statement: Not applicable.

Acknowledgments: Thanks to the School of Gemmology, China University of Geoscience, Beijing.

Conflicts of Interest: The authors declare no conflict of interest.

\section{References}

1. Kolesov, B.A.; Geiger, C.A. Raman spectra of silicate garnets. Phys. Chem. Miner. 1998, 25, 142-151. [CrossRef]

2. Novak, G.A.; Gibbs, G.V. The crystal chemistry of the silicate garnets. Am. Mater. 1971, 56, 791-825.

3. Pinheir, M.V.B.; Basiho, M.S. The cause of colour of the blue alexandrites from Malacacheta, Minas Gerais, Brazil. J. Gemol. 2000, 27, 161-170. [CrossRef]

4. Zhou, D.Y.; Lu, T.J.; Sun, R.D.; Shi, G.H.; Chen, H.; Ke, J. Explanation of the alexandrite effect of zultanite: From the view of colorimetry and chemical analysis. Color Res. Appl. 2019, 44, 925-931. [CrossRef]

5. Shen, C.; Lu, R. The color origin of gem diaspore: Correlation to corundum. Gems Gemol. 2018, 54, 394-403. [CrossRef]

6. Liu, Y.; Shigley, J.; Moses, T.; Reinitz, I. The alexandrite effect of the Tavernier diamond caused by fluorescence under daylight. Color Res. Appl. 1998, 23, 323-327. [CrossRef]

7. Chen, C.Y.; Huang, W.Z.; Shao, T.; Shen, C.; Li, Z.B.; Shen, A.H. The study on UV-Vis spectrum of a special color-changed sapphire. Spectrosc. Spectr. Anal. 2019, 39, 2470-2473.

8. Sun, Z.Y.; Palke, A.C.; Renfro, N.; Breitzmann, H.; Hand, D.; Muyal, J. Discovery of color-change chrome grossular garnets from Ethiopia. Gems Gemol. 2018, 54, 233-236.

9. Promwongnan, S.; Buathong, A. A rare nearly pure end-member grossular garnet with color-change effect. Gems Gemol. 2018, $54,336$.

10. Schmetzer, K.; Hainschwang, T.; Bernhardt, H.-J.; Kiefert, L. New chromium- and vanadium-bearing garnets from Tranoroa, Madagascar. Gems Gemol. 2002, 38, 148-155. [CrossRef]

11. Schmetzer, K.; Bernhardt, H.-J. Garnets from Madagascar with a color change of blue-green to purple. Gems Gemol. 1999, 35, 196-201. [CrossRef]

12. Sun, Z.Y.; Palke, A.C.; Renfro, N. Vanadium- and chromium-bearing pink pyrope garnet: Characterization and quantitative colorimetric analysis. Gems Gemol. 2015, 51, 348-369. [CrossRef]

13. Gübelin, E.; Schmetzer, K. Gemstones with alexandrite effect. Gems Gemol. 1982, 18, 197-203. [CrossRef]

14. Liu, Y.; Shigley, J.; Fritsch, E.; Hemphill, S. The "alexandrite effect" in gemstones. Color Res. Appl. 1994, 19, 186-191. [CrossRef] 
15. Tang, J.; Guo, Y.; Xu, C. Color effect of light sources on peridot based on CIE1976 L*a*b* color system and round RGB diagram system. Color Res. Appl. 2019, 44, 932-940. [CrossRef]

16. Cheng, R.P.; Guo, Y. Study on the effect of heat treatment on amethyst color and the cause of coloration. Sci. Rep. 2020, 10, 14927. [CrossRef] [PubMed]

17. Wang, X.D.; Guo, Y. The impact of trace metal cations and absorbed water on colour transition of turquoise. R. Soc. Open Sci. 2021, 8, 201110. [CrossRef] [PubMed]

18. Guo, Y. Quality grading system of Jadeite-Jade green based on three colorimetric parameters under CIE standard light sources D-65, CWF and A. Bulg. Chem. Commun. 2017, 49, 961-968.

19. Guo, Y.; Zong, X.; Qi, M. Feasibility study on quality evaluation of Jadeite-jade color green based on GemDialogue color chip. Multimed. Tools Appl. 2019, 78, 841-856. [CrossRef]

20. Tooms, M.S. Exploiting colorimetric relationships in characterizing the spectral response functions of the human visual system directly from colour matching functions. Color Res. Appl. 2020, 45, 782-795. [CrossRef]

21. Kasajima, I.; Sasaki, K. Dichromatism causes color variations in leaves and spices. Color Res. Appl. 2015, 40, 605-611. [CrossRef]

22. Kasajima, I. Alexandrite-like effect in purple flowers analyzed with newly devised round RGB diagram. Sci. Rep. 2016, 6, 29630. [CrossRef]

23. Sun, Z.Y.; Palke, A.C.; Muyal, J.; McMurtry, R. How to facet gem-quality chrysoberyl: Clues from the relationship between color and pleochroism, with spectroscopic analysis and colorimetric parameters. Am. Miner. 2017, 102, 1747-1758. [CrossRef]

24. Xie, F.; Cao, Y.; Ranchon, C.; Hart, A.; Hansen, R. Explanation of the colour change in alexandrites. Sci. Rep. 2020, 10, 6130. [CrossRef]

25. Fairchild, M.D. Color appearance models and complex visual stimuli. J. Dent. 2010, 38, e25-e33. [CrossRef]

26. DiDomenico, M.; Wemple, S.H. Oxygen-octahedra ferroelectrics. I. Theory of electro-optical and nonlinear optical effects. J. Appl. Phys. 1969, 40, 720-734. [CrossRef]

27. Wemple, S.H.; DiDomenico, M. Behavior of the electronic dielectric constant in covalent and ionic materials. Phys. Rev. B 1971, 3 , 1338-1351. [CrossRef]

28. Wemple, S.H. Optical oscillator strengths and excitation energies in solids, liquids, and molecules. J. Chem. Phys. 1977, 67, 2151-2168. [CrossRef]

29. Medenbach, O.; Shannon, R.D. Refractive indices and optical dispersion of 103 synthetic and mineral oxides and silicates measured by a small-prism technique. J. Opt. Soc. Am. B 1997, 14, 3299-3318. [CrossRef]

30. Han, Z.Y.; Sun, D.L.; Zhang, H.L.; Luo, J.Q. Investigation on the growth and properties of six garnet single crystals with large lattice constants. Cryst. Res. Technol. 2021, 56, 2000221. [CrossRef]

31. Shen, C. Color quantification of gem corundum. Master's Thesis, China University of Geosciences, Wuhan, China, 2019.

32. Liao, N.F.; Shi, J.S.; Wu, W.M. An Introduction to Digital Color Management System; Beijing Institute of Technology Press: Beijing, China, 2009.

33. ISO/CIE 11664-3:2012(E) Colorimetry_Part 3: CIE Tristimulus Values; ISO: Geneva, Switzerland; CIE: Vienna, Austria, 2012.

34. ISO/CIE 11664-4:2019(E) Colorimetry_Part 4: CIE 1976 L*a*b* Colour Space; ISO: Geneva, Switzerland; CIE: Vienna, Austria, 2019.

35. CIE International Commission on Illumination. CIE15-2004: Colorimetry, 3rd ed.; CIE: Vienna, Austria, 2004.

36. Moore, R.K.; White, W.B.; Long, T.V. Vibrational spectra of the common silicates: I. The garnets. Am. Miner. 1971, 56, 54-71.

37. Hofmeister, A.M.; Fagan, T.J.; Campbell, K.M.; Schaal, R.B. Single-crystal IR spectroscopy of pyrope-almandine garnets with minor amounts of Mn and Ca. Am. Mineral. 1996, 81, 418-429. [CrossRef]

38. Weng, S.F.; Xu, Y.Z. Fourier Transform Infrared Spectroscopy Analysis, 3rd ed.; Chemical Industry Press: Beijing, China, 2016; pp. 10-429. (In Chinese)

39. Schmetzer, K.; Bernhardt, H.-J.; Bosshart, G.; Hainschwang, T. Colour-change garnets from Madagascar: Variation of chemical, spectroscopic and colorimetric properties. J. Gemol. 2010, 31, 235-282. [CrossRef]

40. Moore, R.K.; White, W.B. Electronic spectra of transition metal ions in silicate garnets. Can. Mineral. 1972, 11, 791-811.

41. Taran, M.N.; Dyar, M.D.; Matsyuk, S.S. Optical absorption study of natural garnets of almandine-skiagite composition showing intervalence $\mathrm{Fe}^{2+}+\mathrm{Fe}^{3+} \rightarrow \mathrm{Fe}^{3+}+\mathrm{Fe}^{2+}$ charge-transfer transition. Am. Miner. 2008, 92, 753-760. [CrossRef]

42. Krambrock, K.; Guimarães, F.S.; Pinheiro, M.V.B. Purplish-red almandine garnets with alexandrite-like effect: Causes of colors and color-enhancing treatments. Phys. Chem. Miner. 2013, 40, 555-562. [CrossRef]

43. Schmetzer, K.; Hainschwang, T.; Kiefert, L.; Bernhardt, H.-J. Pink to pinkish orange Malaya garnets from Bekily, Madagascar. Gems Gemol. 2001, 37, 296-308. [CrossRef]

44. Heidi, B.; Breitzmann, H.; Sun, Z.Y.; Palke, A.C. Color-change spessartine garnet: A first report. Gems Gemol. $2019,55,254-257$.

45. Geiger, C.A.; Stahl, A.; Rossman, G.R. Single-crystal IR- and UV/VIS-spectroscopic measurements on transition-metal-bearing pyrope: The incorporation of hydroxide in garnet. Eur. J. Mineral. 2000, 12, 259-271. [CrossRef]

46. Li, L.P.; Ye, D. Role of $\mathrm{Cr}$ and V in colour change effect of gemstones. Gems Gemol. 2003, 5, 17-21. (In Chinese with English abstract).

47. Liu, Y.; Shigley, J.; Fritsch, E.; Hemphill, S. Abnormal hue-angle change of the gemstone tanzanite between CIE illuminants D65 and a in CIELAB color space. Color Res. Appl. 1995, 20, 245-250. [CrossRef]

48. CIE International Commission on Illumination. Available online: http:/ / cie.co.at/technical-work/technical-resources. (accessed on 2 March 2021). 